\title{
New Student Orientation in Online Education
}

\section{Sara Connolly}

This study utilized the standards put forth by the Council for the Advancement of Standards in Higher Education (CAS) to assess orientation in online education. Two surveys were used to examine the oldest and largest online degree programs, as well as all-online schools. Descriptive statistics were employed to compare online orientation practices to the CAS Standards. Results suggest that online orientation programs are meeting the standards in some areas and missing them in others. The demographics and needs of online students must be closely examined in order to define engagement in the online environment.

Online education is growing substantially (Allen \& Seaman, 2010). However, there is little research regarding student services in the online environment. This study seeks to fill that gap by addressing one area of student services in the online environment-new student orientation. The researcher used the standards set forth by the Council for the Advancement of Standards in Higher Education (CAS) to evaluate orientation programs in online degree granting programs. Some of the degree granting programs were found in traditional face-to-face schools that also offer online degrees, while others were found at schools that offer education primarily via distance learning. This study illustrates how new student orientation is conducted in the area of distance education and provides suggestions and ideas for future research related to student services in distance education.

\section{Online Growth}

In 2008, online education increased by $17 \%$ over the previous year; 14.6 million or 1 in 4 students reported taking at least one course online (Allen \& Seaman, 2010). This growth far exceeds the total increase in overall higher education, which was $1.2 \%$ in the same time period (Allen \& Seaman, 2010).

\section{New Student Orientation}

New student orientation programs have been present on college campuses since nearly the beginning of higher education, with the first orientation program offered at Harvard in the 19th Century (Upcraft \& Gardner, 1989). Recently, 
institutions which responded to the National Orientation Directors Survey indicated that they have an in-person orientation experience for their new students (Student Voice, 2007). When orientation programs are planned and implemented following nationally recognized standards, such as those of the Council for the Advancement of Standards, they have been shown to increase academic and social integration as well as student retention and academic achievement (Pascarella, Terenzini, \& Wolfle, 1986; Cuseo, 1997; Fox, Zakely, Morris, \& Jundt, 1993; Hollins, 2004; Gentry, Kuhnert, Johnson, \& Cox, 2006.) This impact on retention is of particular interest to colleges and universities because research has shown that the majority of students who leave school do so voluntarily, and they most choose to leave either during or following their first year of college (Tinto, 1993; Braxton, Hirschy, \& McClendon, 2004).

\section{CAS Standards}

The Council for the Advancement of Standards for Student Services was formed in 1979 to accomplish three goals: (1) create an environment of standards; (2) assist with implementation of those standards; and (3) provide continual evaluation (CAS, 1986). In the area of new student orientation, CAS Standards fall into the following categories: mission, program, leadership, organization and management, human resources, financial resources, facilities and equipment, legal responsibilities, equal opportunity, campus and community relations, diversity, ethics, and assessment/evaluation (CAS, 1997). CAS requires that orientation programs adhere to their standards, which serve as useful and professionally endorsed tools for creating and implementing programs and services in student affairs.

This paper focuses on five of the CAS Standards in terms of enhancing orientation for online education: mission, program, human resources, financial resources, and assessment. First, the mission standard refers to clear directives and outcomes. CAS indicates that orientation programs should have goals that should be reviewed regularly. Second, the programmatic standard encompasses accommodating the needs of all students, including special populations (i.e., students with disabilities, under represented groups, and first-generation students). Orientation programs should be coordinated across the campus; undergo regular self-assessment; help students to understand the purpose of education and the campus they attend; provide information on campus and community services; support families; and provide students with an opportunity to meet and interact with faculty, staff, and continuing students. Third, the human resource standard addresses appropriate staffing issues. Fourth, the financial resources standard assesses how the school funds the orientation program. Finally, the assessment/ evaluation standard examines how well the programs perform and suggests that adjustments or changes be made to the program based on evaluation results (CAS, 1997). 


\section{Methodology}

\section{Survey Instrument}

The items on the survey instrument utilized a variety of questions, including "yes" or "no" questions, "list" questions in which participants checked all that applied, and open-ended questions in which the participants provided their own responses. The survey instrument assessed the following aspects of new student orientation: the mission of the program, specific programmatic aspects of orientation, human resources, financial resources, and assessment/evaluation.

\section{Data Collection}

This study was conducted in two stages. The first phase of the survey, New Student Orientation in Distance Education, was administered to the contacts described in the "Participants" section by The Office of Institutional Effectiveness (OIE) at the researcher's institution in late January/early February of 2008. The second phase of the survey was distributed by the same office in April 2008, using the same procedures. The survey was distributed using SurveyMonkey, a Web-based data collection tool. Participants were given two weeks to respond to the survey, with reminder e-mails sent after one week and just prior to the close of the survey. Participants had the right to "opt out" of the survey (an option available through SurveyMonkey), and informed consent was assumed by submission of the survey. Following the close of the survey, all data were sent to the researcher in aggregate form so the identity of the participants remained confidential.

\section{Participants}

The sample groups for this study were compiled from U.S. News and World Report's (2007) distance education programs. During the first of the two stages of this study, a self-developed survey was distributed to the oldest and largest online degree granting programs as determined by U.S. News and World Report. This group was first included with the idea that the administrators of programs who have been around the longest would have had the most experience with orientation. Additionally, the largest programs would need to consider logistical issues like orientation. After eliminations for incorrect e-mail addresses and other logistical issues, there remained a group of 24 schools. In this first phase of the study, the survey achieved a $42 \%$ response rate.

During the second phase of the study, the survey was distributed to all schools that offer online undergraduate degree granting programs. The initial survey distribution list included 296 schools that offer associate/bachelor's degrees online. After several eliminations due to incorrect e-mail addresses and other issues similar to the first phase, a total of 259 schools were invited to participate in the study. In this phase of the study, the survey achieved a $44 \%$ response rate. 


\section{Results and Discussion}

\section{Mission}

The standards set forth by CAS require that a student orientation program have a clearly stated mission statement. Programs should be based on stated goals. This study found that the majority of online schools did not have a mission statement (33\% of oldest and largest schools, 5.9\% of all-online degree granting programs). It also found that while the majority of the oldest and largest online programs had written goals $(75 \%)$, less than half of all-online programs had written goals $(42.4 \%)$. However, many of the study participants shared the goals of their orientation program which seemed to indicate that, while they were not written, many schools operate with a goal-based program. These goals frequently included providing information on using online technology, as well as resources and services to help students in their transition to their college. This leads to the conclusion that while a majority of schools do not provide a written mission statement, they may be fulfilling the CAS Standard of stated goals even if these goals are not formally presented as a statement.

\section{Program}

This study addressed the following CAS programmatic standards for orientation: availability to all, coordination across campus, helping students understand higher education, and informational pieces (1997).

Availability to all students. A majority of schools are meeting this standard in that $80 \%$ of oldest and largest schools and $71.3 \%$ of all-online degree granting programs offer an orientation program for their online students. This program is different from the orientation program offered to the students who take classes on the ground campus. A closer examination showed that orientation is often optional for online students, and not all students participate. It is not clear from this study what percentage of students participate in the optional orientation program for online education.

Coordination across campus. Approximately half of participating schools indicated that there is some coordinated effort from across the campus, with 2-4 offices participating in the planning and implementation of the orientation program. However, approximately $37 \%$ indicated that no other offices participate in the planning; therefore, these online orientation programs are not meeting the CAS Standards in this area. Taken together, these statistics indicate that orientation is largely planned and implemented by one office, and this is most often the office that is in charge of distance education. It is possible that coordination in online education happens when the program is first created, and that the self-sustaining program does not require further collaboration after this initial creation stage.

Helping students understand higher education. In three separate survey questions, participating schools indicated whether or not their program included 
information on general education, benefits of a college education, and the purpose of their college or university. A majority of the schools in the oldest and largest group $(80 \%)$ indicated that they provide information on general education and the purpose of the college or university, while fewer than $40 \%$ of the schools in the all-online education group noted that they include this information. Most schools from both groups indicated that they do not give information on the benefits of a college education. This suggests that most schools are not meeting this CAS requirement in this programming area.

Informational pieces. CAS Standards indicate that elements such as university policies and procedures, expectations and responsibilities, as well as resources and services need to be included in orientation programs for new students (CAS, 1997). As seen in Figure 1, the schools in both groups are meeting the standard of providing these informational pieces to students. The online schools inform their students about the services available to them and address policies, procedures, and logistical concerns. This may include an in-depth tutorial on how to use the platform utilized for their online courses. This is somewhat equivalent to the campus tour in traditional orientation as it is crucial that students know how to get around the platform in order to be successful. A strong tour of the platform would include finding the seminar, using the libraries, locating instructors' office hours, and using the online asynchronous discussion boards that the students will use weekly to talk about what they are learning in their classrooms.

While the online schools are fulfilling some of the CAS programmatic standards, they are falling short on some others, as seen in Figure 1. Online schools do not offer many opportunities for new students to meet or interact with their peers, faculty, or staff. Very few online schools indicated that they offer placement testing or address logistical concerns. However, it should be noted that when asked about their goals for orientation, many of the online schools relayed that they offer an opportunity for students to assess their readiness for online learning. This may indicate that self-assessment in the online environment is fundamentally different than self-assessment in the more traditional face-to-face classroom.

\section{Human Resources}

In order to assess how online orientation programs fulfill the CAS Standards in the category of human resources, participants were asked a series of questions regarding their staffing patterns. The results indicated that, in most programs, a professional staff member has responsibility for orientation, but students are seldom utilized for staffing (75\% of oldest and largest schools and $89 \%$ of all-online degree granting programs do not utilize student staff). This may be because online orientation programs are more self-sustaining than ground orientation programs. While ground orientation programs generally bring the new students to campus and lead them through a series of programs, online orientation programs are most often run through their online classroom space. This model allows the program to be built ahead of time and is then self-sustaining. This may 


\section{Programmatic Elements Included in Online Orientation}

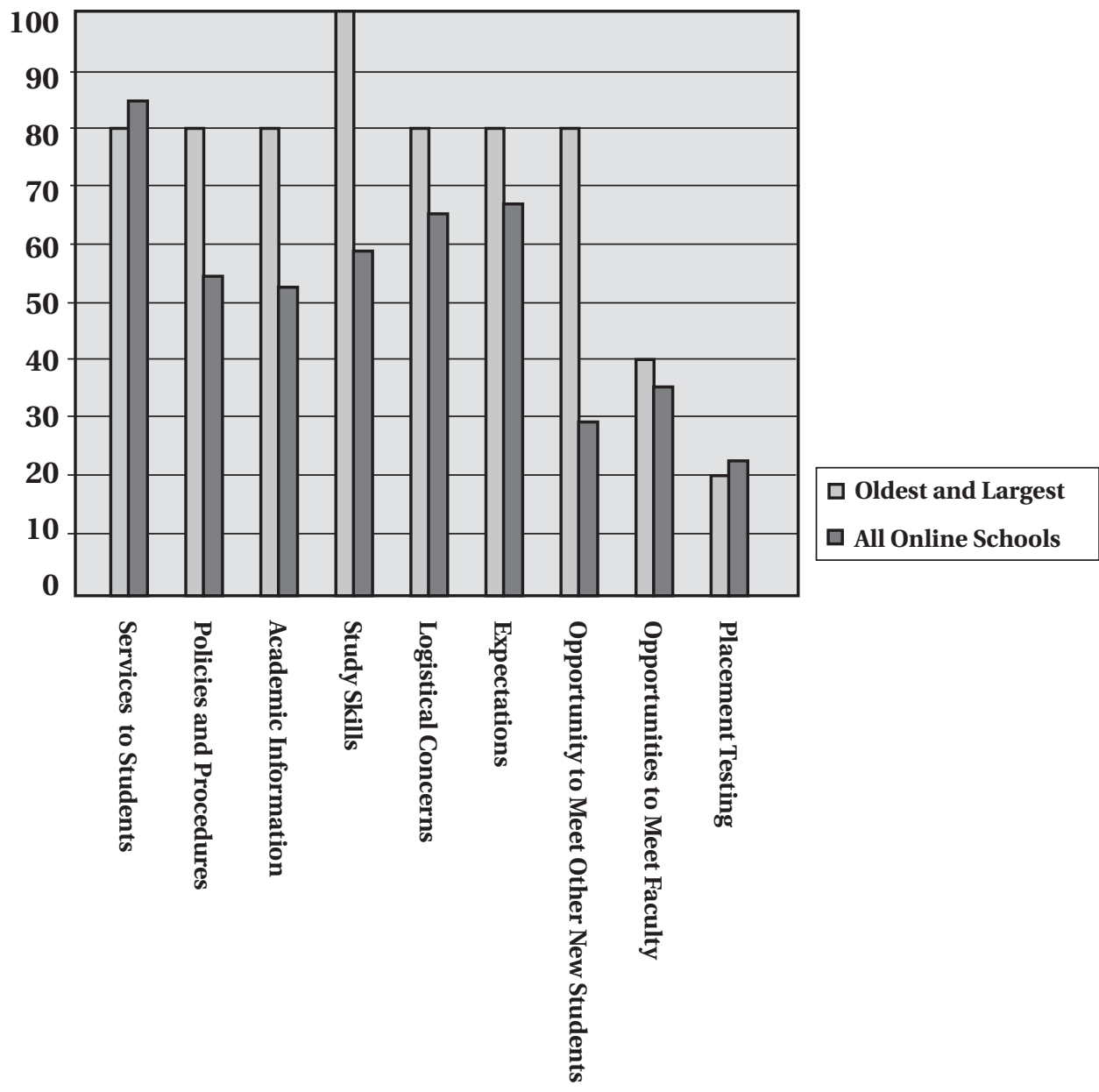

mean that a great deal of work needs to go into creating the program, but student staff members are not needed to assist in implementation as they are in ground orientation programs. While the CAS Standards additionally indicate that student staff should be trained and evaluated. The lack of student staff used in online orientation programs made these standards non-applicable in the online environment (CAS, 1997). 
CAS Standards indicate that there should be an institutional financial commitment to orientation programming, and a small fee should also be charged to participants to help offset costs (1997). The majority of the participants $(62.8 \%$ of all-online schools and $100 \%$ of the oldest and largest schools) indicated that the online orientation program is funded through the university general fund, which meets the CAS Standard of an institutional financial commitment. However, 41.1\% of the participants also indicated that there is no cost to run their orientation program. This again speaks to the nature of online orientation program. The cost in online orientation program largely comes from the time and energy used to create the program, but it is often self-sustaining once it is established. Therefore, there may not be a need to request yearly funds in the budget or to create a new student orientation fee for online orientation programs (CAS, 1997).

\section{Assessment}

In the area of evaluating orientation programming, the majority of the oldest and largest online programs (80\%) and slightly less than half $(48.4 \%)$ of all-online schools indicated that they assess their program and use the results to improve their orientation process. Of those schools that evaluate their orientation program, most conduct surveys, and a few use focus groups. However, the fact that half of the online schools in the larger group do not evaluate their program suggests that there are many schools that are not meeting this CAS Standard. Like staffing and funding, this could be because of the nature of online orientation. Because the online program is self-sustaining, it may be easier to skip the evaluation stage and leave the program to run without changes.

\section{Limitations}

There are two major limitations in this study—the small size of the first group surveyed and the age of the CAS Standards used in this study. The first survey group consisted of 24 schools. These were the oldest and largest online degree granting programs, as listed in U.S. News and World Report (2007). This first survey received a $42 \%$ response rate. While this is an acceptable response rate, it leaves a very small sample. As stated previously, there were some differences between the oldest and largest survey group, and the group that included all-online degree programs. Due to the small size of the oldest and largest group, it is difficult to determine if the differences displayed are real or due to small response sizes.

The CAS Standards utilized for this study were published in 1997. In 2009, a seventh edition of CAS Professional Standards for Higher Education was published. While some of the same standards for orientation programs are present from the 1997 edition to the latest edition, each has been rewritten to provide new details. Similar to those used for this study, the seventh edition outlines standards in the 
areas of mission, program, leadership, organization and management, human resources, financial resources, facilities and equipment, legal responsibilities, equal opportunity, campus and community relations, diversity, ethics, and assessment/ evaluation. The newer versions of CAS add standards in the areas of access and affirmative action technology and facilities and equipment. The newer CAS Standards set specific guidelines for orientation directors on and off campus, make note of the need to recognize and promote diverse and accepting environments, and address the need to utilize technology where appropriate. As the seventh edition of CAS (2009) was published after this study was completed, the survey could not reflect the standards outlined in that version. It should be noted that these new standards do not address the use of online orientation, either for online education programs or as a supplement for traditional face-to-face orientation programs, despite the growth in online education (Allen \& Seaman, 2010).

\section{Implications for Practice}

CAS Standards offer guidelines for effective orientation programs. This study found that online orientation programs are not meeting CAS Standards in all areas. Schools that offer online degrees should conduct a self-study to assess how they are meeting the standards and determine areas of improvement. This study found that many of the orientation programs offered to online students are optional. While the program is optional, the goals of the program include important items such as easing the transition to college, using technology, finding services and resources, and assessing whether the online environment is a good fit for the individual student. It would be advantageous for online schools to consider requiring their students to participate in orientation.

Research indicates that social integration, including interaction with peers and faculty, is beneficial to students (Pascarella \& Terenzini, 1991; Tinto, 1993; Cuseo, 1997; Woosley \& Miller, 2009). Social integration includes interacting with peers as well as faculty. Online programs should find ways to increase the contact between new students and their peers (new and continuing students), as well as with the faculty during orientation. This may help to ease students' transition and to raise retention rates.

Due to the self-sustaining nature of online orientation programs it may be tempting to skip the evaluation stage and allow the program to keep running in its current form. However, CAS has recommended that orientation programs utilize evaluation to improve their program. All online orientation programs should find a way to include evaluation as a part of their orientation, and the results should be reviewed and utilized to make changes in their orientation process as necessary.

\section{Recommendations for Future Research}

The first recommendation is to extend the study to other areas of student services. CAS Standards are available for several areas of student services, and 
this study can be extended into these areas using similar research methods. Alternatively, researchers might compare online student services to those provided by the ground campus environment. This study provided a valuable start to research in online student services, but there is much more knowledge to be gained in other areas, such as career services, student activities, advising, and financial aid among others.

An additional research project may look at the needs and demographics of online students. If their demographics differ from the students who enroll in classes in the face-to-face classroom, it may be that their needs are different, and the standards created for services in the classrooms may or may not be applicable to the online environment. An examination of who the students are and what they need will help faculty and administrators to design appropriate programs and services for this group.

A significant contribution to literature on online students and services could be made if a researcher defined and examined engagement in that area. The results of this survey as well as experience in the online classroom suggest that engagement in the online environment might be fundamentally different from engagement in the face-to-face institution. This area needs to be explored further, and a definition needs to be developed. Once engagement within an online environment has been defined, it can be assessed in terms of impact on retention and learning. Further research can determine which schools are excelling in online programs and why.

\section{Summary and Conclusion}

This study provided information regarding practices of online orientation programs. While the presence of online orientation is growing, there is a lack of research regarding student services in the online environment. This study begins to fill that gap, creates implications for practices, and suggests avenues for future research.

Online schools meet only some of the standards outlined by CAS, specifically lacking in the areas of providing students with opportunities to interact with one another and faculty, operating with a specifically stated mission statement, and in coordinating orientation with offices across campus. If online programs are to keep pace with their growth and popularity and compete with ground schools, it behooves them to adhere to principles consistent with nationally recognized standards, such as increasing academic and social integration, as well as student retention and academic achievement. 
Allen, I. E., \& Seaman, J. (2010). Learning on Demand: Online Education in the United States, 2009. Babson Survey Research Group. Retrieved from http://www.sloan-c.org/publications/survey/pdf/learningondemand.pdf

Braxton, J. M., Hirschy, A. S., \& McClendon, S. A. (2004) Understanding and reducing college student departure. ASHE-ERIC Higher Education Report (Vol. 30, No. 3). San Francisco: Jossey-Bass.

Council for the Advancement of Standards in Higher Education. (1986). General standards. Washington, D.C.: Author.

Council for the Advancement of Standards in Higher Education. (1997). The book of professional standards for higher education. Washington, D.C.: Author.

Council for the Advancement of Standards in Higher Education. (2009). CAS professional standards for higher education (7th ed.). Washington, DC: Author.

Cuseo, J. B. (1997). Freshman orientation seminar at community colleges: A research-based rationale for its value, content, and delivery. Unpublished manuscript. Retrieved from ERIC database. (ED411005)

Fox, L., Zakely, J., Morris, R., \& Jundt, M. (1993). Orientation as a catalyst: Effective retention through academic and social integration. In M. L. Upcraft, R. H. Mullendore, B. O. Barefoot, \& D. S. Fidler (Eds.), Designing successful transitions: A guide for orienting students to college (pp. 49-59). (Monograph Series No. 13). Columbia, SC: University of South Carolina, National Resource Center for the Freshmen Year Experience.

Gentry, W. A., Kuhnert, K. W., Johnson, R. M., \& Cox, B. D. (2006). Even a weekend works: The value of a weekend-long orientation program on first-year college students. The Journal of College Orientation and Transition, 14(1), 26-38

Hollins, Jr., T. N. (2004). Participation in an extended orientation course and its relationships with student involvement, student satisfaction, academic performance, and student retention (Doctoral dissertation, The Florida State University, 2004). Retrieved from http://etd.lib.fsu.edu/theses/available/ etd-03212004-230223unrestricted/01dissertation.pdf

Student Voice: Databank Round 3 - Programming. (2007). National Orientation Directors Association Databank. Retrieved from https://www.studentvoice.com/app/ClientWeb/Results.aspx?ProjectId=10227

Pascarella, E. T., Terenzini, P. T., \& Wolfle, L. M. (1986). Orientation to college and freshman year persistence/withdrawal decisions. The Journal of Higher Education, 57(2), 155-175.

Pascarella, E. T., \& Terenzini, P. T. (1991). How college affects students: Findings and insights from twenty years of research. San Francisco: Jossey-Bass.

Tinto, V. (1993). Leaving college: Rethinking the causes and cures of student attrition (2nd ed.). Chicago: University of Chicago Press.

Upcraft, M. L., Gardner, J. N., \& Associates. (1989). The freshman year experience: Helping students survive and succeed in college. San Francisco: Jossey-Bass. 
U.S. News and World Report. (2007). Retrieved December 15, 2007, from http://www.usnews.com/directories/online-education/main/index_html/level+u/ Woosley, S. A., \& Miller, A. L. (2009). Integration and institutional commitment as predictors of college student transition: Are third week indicators significant? College Student Journal, 43(4), 1260-1271. 